\title{
Nordeste - da ocupação às mudanças que influenciam os hábitos e modificam os estilos de vida
}

\author{
Laina Ramos dos Santos ${ }^{1}$
}

Durval Muniz de Albuquerque Júnior é doutor em História pela Universidade Estadual de Campinas - UNICAMP e professor titular da Universidade Federal do Rio Grande do Norte - UFRN, além de colaborador da Universidade Federal de Pernambuco - UFPE e atual presidente da Associação Nacional de História (ANPUH). Publicou diversos livros, como o clássico "A invenção do Nordeste e outras artes". Em entrevista a ComSertões, o professor elucida um pouco mais sobre a ocupação do Nordeste e suas formas de representação e lista os principais símbolos dessa região.

\section{Professor como inicia a povoação do Nordeste do Brasil? E como as figuras do cangaceiro, vaqueiro, jagunço surgem nesse contexto?}

Durval Muniz (DM): A ocupação do sertão, das capitanias que hoje está na área que se chama de Nordeste foram ocupadas a partir da expansão do litoral, no momento em que a Coroa Portuguesa proíbe a criação do gado junto as plantações dos canaviais. Existe aí uma separação das duas economias, à medida que a cana - de - açúcar se torna a principal fonte de riqueza da colônia. Daí a criação de gado vai se internalizar, vai para o interior que é uma coisa ecologicamente, completamente problemática, porque a caatinga não é uma área para se criar gado, ela não é adaptada. Isso significa dizer que o gado vai causar uma destruição bastante importante na região do Semiárido. Essa penetração vai se dar através dos rios, isso porque uma das divisões tradicionais do território do sertão são as ribeiras, o gado era marcado com um símbolo da ribeira que ele pertencia, ou seja, que margem do rio a fazenda estava. É uma penetração extremamente violenta, porque vai sofrer evidentemente a resistência das tribos indígenas, então a ocupação desse território vai se dar através do confronto com os índios, da matança de muito deles. Que também serão utilizados como mão - de - obra, o que quer dizer que a origem mais remota do que se chama vaqueiro, na verdade, são descendentes de índios quando não são índios domesticados, que vão ser utilizados para tomar conta do gado. Gado esse que era criado em sua maior parte à solta, não

\footnotetext{
${ }^{1}$ Graduada em Comunicação Social - Jornalismo em Multimeios pela Universidade do Estado da Bahia (UNEB).
} 
tinha ainda a cerca, as divisões das fazendas não eram distintas, os rebanhos se misturavam, e por isso em determinado momento do ano existia o que se chamava "apartação". Os vaqueiros iam separar os rebanhos, essa é também a origem mais antiga da vaquejada. A vaquejada é originada da separação do gado, porque na época se fazia o que se chamava "fazer a sorte" porque os vaqueiros eram pagos em espécie, eles cuidavam dos rebanhos durante um ano, no final do ano tinham um número de bezerros das crias nascidas, era uma porcentagem podia ser a quarta parte, a terça parte, o que permitia que esses homens fossem criando seu pequeno rebanho. A figura do escravo é uma efígie que aparece à medida que esses homens vão ficando mais riscos, os escravos são utilizados nas tarefas agrícolas ou até mesmo lado -a lado com os senhores e os vaqueiros no trato com o gado. Porque algo interessante na sociedade do sertão é que os patrões muitas vezes trabalhavam ao lado dos empregados e vestiam as mesmas roupas, tinham um estilo de vida mais ou menos parecido, próximo. Essa conquista do interior que vai dar origem a muitos enfrentamentos, pela disputa da terra à medida que vai chegando mais pessoas para ocupar, e as divisões das terras são muito imprecisas, o que gera muitos conflitos e as famosas guerras entre famílias no interior dessa área do sertão. Duas famílias começam a se matar por gerações, isso advém de conflitos em torno da terra e conflitos também políticos. Porque a medida que o Brasil fica independente e se instala o Estado Nacional, essas figuras vão ser os potentados locais, e vão ser representantes fundamentais na máquina política que irá se formar. E aí se têm o surgimento de uma outra figura fundamental do sertão que vai ser o "jagunço". Muitas vezes o vaqueiro transita pelo jagunço, que é essa pessoa que vai se armar para proteger as terras do coronel, proteger o rebanho e proteger a vida do patrão. O jagunço é uma figura importante e que vai dar origem a figura do cangaceiro, porque o cangaceiro é o jagunço que se torna independente do coronel, e passa a viver um estilo de vida próprio, passa a existir o saque, a chantagem como modo de vida.

\section{Pelo o que se interpreta é que os personagens do Nordeste são parecidos entre si, como eram constituídas as relações entre eles?}

Durval Muniz (DM): Elas se interligam porque a base da organização brasileira é a família, isso quer dizer que a única instituição que vertebra a sociedade desde o começo é a família. Porque nós não temos um estado localizado no interior do nosso território, e pertencemos ao Estado Português ou Estado Espanhol, que por sinal estar fora do próprio território, ou seja, durante todo o período colonial o único momento que você têm a presença de um Estado aqui 
é durante o domínio Holandês, mais durante um curto intervalo de tempo. Normalmente o Estado têm uma presença muito distante daqui, é claro que existe as instituições estatais, mais ainda assim elas são distantes, normalmente, localizadas no litoral e possuem pouca capacidade de atuação no interior. A mesma coisa é a igreja católica que está presente mais de uma forma muito dispersa pelo território, a igreja possui pouca capacidade de penetração no interior, então sendo assim a instituição que vertebra a sociedade sertaneja é a família. Tudo gira em torno dela e não é o modelo de família nuclear burguês, é o modelo de família extenso aristocrático medieval, o que quer dizer que ao lado do núcleo da família (pai, mão e filhos) existem toda parentela mais os agregados. É uma família grande, então, temos aí os compadres, os comadres e, por isso, o apadrinhamento é algo tão fundamental na sociedade brasileira, o nepotismo, indicar filhos, netos, sobrinhos para cargos públicos. E daí se dá uma das justificativas para o familismo, a família é a base de tudo e em torno dela gira todos esses personagens, quer dizer o vaqueiro é um agregado, ele possui sua família mais ao mesmo tempo ele é um agregado da família de um coronel, a mesma coisa é o jagunço. Muitas vezes um jagunço é um vaqueiro que cometeu um crime, e é protegido pelo coronel para não ser preso e é utilizado como essa figura que vai portar armas para defender, proteger e servir ao coronel. O cangaceiro surge daí, as principais lideranças do cangaço não são homens pobres, como a historiografia tende a passar, personalidades como Antônio Silvino, Lampião, Corisco eram homens filhos de proprietários de famílias periféricas, agregadas a uma família central.

\section{Existe uma aproximação muito grande entre os nordestinos e os símbolos da região como missas, santos, vestimentas de couro a que se deve e como atuam essa relação?}

Durval Muniz (DM): Isso estar ligado ao surgimento da identidade regional nordestina, que é uma coisa do século XX. O Nordeste emerge na década 1910, e essa ideia vai surgindo no processo de declínio econômico e político das elites dessa área. Então, a ideia de Nordeste surge basicamente no Movimento Regionalista e Tradicionalista do Recife - PE. A capital pernambucana é o lugar de elaboração dessa ideia por isso, até hoje o Recife se considera capital do Nordeste e fala em nome do Nordeste. Você veja que o jornal da noite de Pernambuco não é PE - TV é NE - TV, enquanto todos os outros estados é RN - TV, PB TV. Vale mencionar a importância do jornal $O$ Diário de Pernambuco na construção dessa identidade, porque ele era um jornal que alcançava toda a região e se você observar edições do Diário de Pernambuco 1924 - 1926, todas as reuniões do Centro Regionalista estão descritas no jornal e ele participava da criação da identidade Nordeste. A ideia de Nordeste 
possui dois elementos fundamentais em sua definição, a sua natureza, a ideia de que o Nordeste é semiárido é sujeito a seca e, portanto, ele é distinto das outras áreas do país, embora a gente sabe que isso é uma homogeinização da natureza do Nordeste, porque existem áreas que não são semiáridas, mais a ideia e que o Nordeste é todo semiárido e o outro ponto a destacar e a dimensão cultural. A ideia de que nós temos uma cultura particular, pelo fato da cultura dessa parte da região não ter sofrido influências estrangeiras. Porque como não houve a imigração estrangeira para cá, a gente "preservaria" aquela cultura que vêm das raízes Ibéricas, que vêm da influência Moura, Judaica porque judaicos, mouros e europeus conviveram na Península Ibérica. A ideia de cultura nordestina que temos na cabeça até hoje foi construída pelos folcloristas no começo do século XX. Esses estudiosos do que se chama folclore apontam que é o momento em que as elites tradicionais estão em declínio, e começam a sentir saudade de costumes, hábitos, tradições que caracterizavam um modo de vida que estava desaparecendo com a vida moderna, urbana, e com o capitalismo. No meu livro $A$ Feira dos Mitos (2013), têm um capítulo que se chama "E com a queda que se enxerga o pó", então como essas elites estão declinando começam a enxergar que aquilo que percebiam como cultura menor, que no máximo era esteticamente interessante, curiosa as elites passam a valorizar as manifestações culturais, pelo desaparecimento e essas manifestações ainda nas camadas populares. Como a vida dos coronéis do Sertão não são muito diferentes dos que viviam em torno dele, as relações eram mais ou menos iguais. Se um usava chapéu de couro o outro usava, se um usava gibão o outro usava, era comum no interior que o coronel chamasse os trabalhadores para comer na varanda da casa, em pé mais comia junto com eles. Comiam a mesma coisa, a qualhada, o cuscuz todos dormiam em rede, quase não existia cama, porque eram caras e precisavam ser importadas e transportada para o Sertão. Sendo assim, todos acabaram adotando modos de vida dos indígenas, passou-se a usar os utensílios como gamela, colher - de - pau, chapéu de palha. Os hábitos alimentícios também foram influenciados como a mandioca, o milho, a tapioca que são também a base da culinária nordestina. Então, os folcloristas tomaram essas manifestações culturais, objetos e etc. Tal distinção é percebida entre as classes dominantes e camadas populares e, justamente nessa última, que se encontra o que vai se chamar de processo de folclorização. Porque um objeto se torna folclórico normalmente quando ele deixa de ser usado pelas elites, por exemplo: enquanto as elites usavam o chapéu de couro, ele não era folclórico, era uma coisa de uso comum, habitual. A medida que as elites passam a usar o chapéu de massa ou de palhinha o então chapéu de couro passa ser folclórico. Então, é um determinado estilo de vida que está ficando para trás e que as 
elites têm saudade e aí nomeia isso de cultura nordestina. Assim como o Nordeste surge da saudade de um determinado tempo de glória, é visto como algo do passado, a cultura também é percebida como uma cultura tradicional, artesanal, não - industrial, não - moderna.

\section{O que vêm a ser o conceito de cultura popular e como ela dialoga com o conceito de} Cultura?

Durval Muniz (DM): O conceito de cultura popular é um conceito que vai surgir a partir dos anos 40, do século XX, e ele estar vinculado inicialmente a uma visão de esquerda, são autores marxistas que vão em grande medida elaborar essa ideia. Ela surge da política cultural do Estado Novo, uma ideia de construção de cultura que seria nacional e o que seria a base dessa cultura nacional, seria o que se chama de cultura popular. Luiz Gonzaga vai para a Rádio Nacional, criada pelo regime Vargas para construir a ideia de cultura nacional, a rádio é para interligar todas as diferenças regionais. O governo Vargas inclusive vai combater os regionalismos e os símbolos regionais e estaduais e vai enfatizar a ideia de nação. Nesse projeto, a rádio têm a função de criar a gênese dessa cultura nacional através da música. Luiz Gonzaga é contratado pela Rádio Nacional para representar o que seria a música nordestina, inclusive é o que leva a ele pensar: $\mathrm{O}$ que é uma roupa nordestina? E aí ele têm a ideia de não só cantar o que seria a música do Nordeste, mais se vestir como nordestino, e aí ele lembra do gibão de vaqueiro e o chapéu de cangaceiro. A cultura popular surge em um determinado momento histórico e vai recobrir determinados elementos da realidade, da empiria e aí você vai dizer o que é cultura popular, o que não é. O conceito de cultura é complexo justamente porque tudo é cultura, o homem é um ser cultural, tudo o que ele produz é cultural como cultura é tudo fica difícil dizer o que é, pois, todas as dimensões humanas são culturais. A economia é cultural, a política é cultural e essa ideia de cultura popular justamente é possível, porque se têm esse momento de profunda distinção das culturas entre as classes sociais, com o desenvolvimento do capitalismo a influência das cidades, do meio urbano que vai modificar profundamente as formas de viver do campo e da cidade.

\section{A discussão sobre o Nordeste levanta e divide opiniões e chega a causar incômodo em outras regiões do país, de que maneira essas percepções são percebidas e como são interpretadas?}

Durval Muniz (DM): O preconceito contra os nordestinos é imenso, não é difícil nos depararmos com nomenclaturas de baixo escalão e sentimentos genocidas de liquidação dos 
nordestinos. Estava acontecendo um movimento recente no Sul do país de separação e eles desejavam realizar um plebiscito para saber se separava ou não e a justiça proibiu, um dos motivos é o desejo de separação do Nordeste. A ideia de que somos atrasados, que nós somos um peso morto, que não produzimos nada, não trabalhamos, que todos somos preguiçosos e que ficamos com a maior parte dos recursos federais. Então, a uma visão totalmente distorcida, e o regionalismo nordestino que é incorporado pela própria população do Nordeste faz parte da nossa identidade. O Nordeste é efetivamente a única região que existe no Brasil, as outras são mera convenção política - administrativa. Ninguém no Sudeste se sente sudestino, ninguém no Sul se sente sulista, ninguém no Centro - Oeste se sente centroestino, mais nós no Nordeste nos sentimos nordestinos. Além de pernambucanos, paraibanos, cearenses, baianos, nós nos sentimos nordestinos. Essa identidade ela é introjetada, arraigada, subjetivada e muito forte. O problema é que essa identidade, ela é uma identidade degradada, a identidade nordestina é marcada pelo complexo de inferioridade. Internalizar que é nordestino é internalizar que é menor, que é menos, é internalizar que é atrasado, que é subdesenvolvido. Existe uma certa reação nas classes médias - urbanas em relação a essa identidade, eu digo isso porque toda minha crítica a identidade nordestina nasce disso, porque sou um rapaz de classe média urbana e por isso as classes médias urbanas têm uma cação a essa identidade, pois, percebem o quanto ela é uma identidade degradante.

\section{As mudanças acontecem independente da vontade das pessoas até que ponto elas podem alterar o comportamento e estilos de vida dos nordestinos?}

Durval Muniz (DM): Uma coisa só sobrevive na cultura enquanto ela faz sentido para as pessoas, quando elas deixam de fazer sentido para as pessoas elas desaparecem. A sociedade muda os personagens, caem no esquecimento, as pessoas desaparecem, os lugares de sujeito desaparecem, pois, esses lugares são distribuídos pela sociedade. O vaqueiro, por exemplo, é um lugar que significava um estilo de vida, uma forma de se vestir, de se comportar, uma série de coisas que não adianta você tentar manter artificialmente. Nós estamos dentro de uma sociedade que destrói formas tradicionais de vida, o capitalismo se revoluciona a si mesmo, ele destrói formas que ele próprio cria, o que dirá formas anteriores a ele?

\section{Na sua opinião o que se espera acerca das discussões sobre o Nordeste?}

Durval Muniz (DM): Nós podemos ser sem ser Nordeste. Podemos viver com um outro recorte espacial, mais a gente também pode viver com a ideia de Nordeste, mas reelaborando 
ela. Precisa trabalhar essa ideia de reelaboração, porque ela serviu até hoje para reproduzir as relações de poder mais arraigadas da sociedade, a exploração de algumas famílias e alimenta a política famialista. Um exemplo é o filme Boi Neon que, na minha opinião, é um investimento no sentido de reelaborar a imagem da região. $\mathrm{O}$ cinema tem uma importância muito grande nisso com Aquarius ou Som ao Redor, quer dizer uma série de filmes, da filmografia pernambucana, têm dado uma contribuição muito grande nessa ideia de reelaboração necessária da ideia de Nordeste, porque quando se fala em Nordeste, em sua maioria, o imaginário que aparece é o do atrasado, do passado e das relações de poder desiguais. Nós somos uma região que possuímos três das grandes metrópoles do país, somos uma sociedade majoritariamente urbana, e com problemas urbanos como a violência, má ocupação do solo e indisponibilidade de espaço. Essa visão romantizada da ideia de Nordeste não precisa deixar de existir precisa (re)significar, e compreender que temos problemas contemporâneos e que existem coisas e personagens que realmente precisam ficar no passado. 